\title{
Cirrus Clouds and Multiple Tropopause Events over Buenos Aires
}

\author{
Susan Gabriela Lakkis ${ }^{1,2 *}$, Mario Lavorato ${ }^{3}$, Pablo Osvaldo Canziani ${ }^{2,4}$, Héctor Lacomi ${ }^{3}$ \\ ${ }^{1}$ Facultad de Ciencias Agrarias, Pontificia Universidad Católica Argentina, Puetro Madero, Argentina \\ ${ }^{2}$ Equipo Interdisciplinario para el Estudio del Cambio Global, Pontificia Universidad Católica Argentina, Puetro \\ Madero, Argentina \\ ${ }^{3}$ División Radar Laser, CEILAP (CITEFA - CONICET), Buenos Aires, Argentina \\ ${ }^{4}$ Consejo Superior de Investigaciones Científicas y Técnicas (CONICET), Argentina \\ E-mail:gabylakkis@uca.edu.ar \\ Received March 10, 2011; revised April 15, 2011; accepted April 29, 2011
}

\begin{abstract}
Lidar measurements of midlatitude cirrus clouds over Buenos Aires, collected between 2002 and 2003, are compared with multiple tropopauses (MT) retrieved from rawinsonde temperature retrievals. Results derived from the rawinsondes display MT events with an annual cycle which are fewest in March. Comparison with lidar observations shows that cirrus clouds are mostly located closely below the first tropopause, but when cloud top is above the first tropopause, in $25 \%$ of cases, the cloud base is not above it, resulting in a cirrus cloud crossing the inter-tropopause region. Compared with the distribution of the whole population of midlatitude cirrus clouds, cross-tropopause cirrus clouds display a similar geometrical thickness as inter-tropopause cirrus clouds.
\end{abstract}

Keywords: Multitropopause Events, Cirrus Clouds, Lidar

\section{Introduction}

Cirrus clouds play an important but uncertain role in the Earth's climate system [1]. They cover about $30 \%$ of the Earth's surface at any one time, and play an important role in the Earth's climate system owing to their capability of trapping outgoing long-wave (greenhouse effect) and reflecting solar radiation (albedo effect) as well as in the troposphere - stratosphere exchange [2]. Due to their ubiquitous nature and higher altitude, the properties of these ice clouds are particularly difficult to characterize. Moreover, the properties of tropical cirrus are distinct from those of the midlatitudes. While the cirrus clouds form at higher altitudes and where temperatures are much lower, is usually termed as "cold cirrus", its counterpart in midlatitudes forming at relatively lower altitudes associated with comparatively higher temperatures are called "warm cirrus" [3]. Moreover, at small scale, their properties are directly related to the local phenomena [4], and therefore it is difficult to ascertain if they can be parameterized with accuracy, even when only considering constrained latitude areas [5]. Since cirrus cloud population may be increasing as consequence of the climate change, improving our understanding of these clouds is an important challenge.

The tropopause is a layer formed due to natural atmospheric temperature inversion, which separates the troposphere from stratosphere. This layer is recognized as a key feature of the atmospheric structure at all latitudes; i.e., polar, mid latitudes and tropics, and an overall understanding both of the upper troposphere - lower stratosphere (UTLS) and of the stratosphere-troposphere exchange (STE) is dependent on our ability to quantify and describe tropopause structures and their evolution in time [6-9].

The tropopause or rather the tropopause layer [10] in simple terms determines the boundary between the troposphere and stratosphere, which has fundamentally different characteristics with respect to chemical composition and static stability. The tropopause can be thus viewed as the transition zone between the turbulently mixed troposphere and the more stable stratified stratosphere [11], affecting both the dynamics and the chemistry. This natural layer plays a significant role in the STE as various minor constituents enter stratosphere from troposphere through this region and vice versa [12]. Due 
to the high altitude of the cirrus clouds, their formation process as well as their evolution may be related to the upper troposphere-lower stratosphere coupled system; thus, studying UTLS conditions could provide insights on cirrus clouds formation processes and their properties [13]. The tropopause temperature could influence the clouds altitude and therefore, the thermodynamic of the atmosphere; hence, the variability in the tropopause could affect the properties of the tropopause cirri, especially those located within the UTLS area. The multiple inversions in the UTLS area represent the tropopause events (MT). Considering that the variability in the thermodynamic structure of the tropopause could affect the properties of the tropopause cirri, several recent analysis have focused on tropical and midlatitude tropopause cirri properties, bearing in mind that temperature inversion has a constraining effect on cloud altitude $[2,14,15]$.

Recently Nöel and Haeffelin [13], analyzed the cirrus clouds and multiple tropopause events correlation over Sirta by means of the ratio of the distance between the first tropopause and cloud top to the distance between MT. Using this definition about the ratio defined by them, we studied the MT events but over Buenos Aires (EZE; $34.6 \mathrm{~S}, 58.5 \mathrm{~W}$ ) during 2002-2003 and attempts to investigate the possible relationship between MT events and cirrus clouds occurrence.

\section{Observations}

To analyze the behaviour of the multiple tropopauses related to cirrus clouds, in situ rawinsondes and remotesensing observations collected between 2002 and 2003 were used for the present analysis. Tropopause levels were retrieved from temperature profiles obtained through a data set of radiosoundings launched (12 UTC) from the Servicio Meteorológico Nacional (SMN). The simultaneous study of ice clouds involved finding a data source suited to the detection and analysis the cirrus clouds.

Various techniques have been developed during the past decades to detect cloud occurrences from passive remote-sensing observations by spaceborne radiometers [16], satellite observations and analysis using passive cloud-imager data, such as cloud-top height (e.g., [17,18]) or microphysical properties [19]. Nonetheless these techniques can include significant biases due to the ubiquitous and semitransparent nature of those clouds. This precludes the use of passive remote-sensing data to study interactions between the thermodynamic structure near the UTLS and cirrus cloud properties. Therefore, other observations are required to obtain a realistic estimate of the ice cloud cover. Due to the capability of the laser beam to point upward into the atmosphere and their high sensitivity to atmospheric layers, lidar system have be- come the standard tool to analyze the clouds and their time and spatial evolution. Moreover, most modern lidar systems are equipped with the ability to read the polarization state of the backscattered light [20], providing insights into the cloud phase [21], geometric and optical properties [2] and microphysical properties [22]

The elastic backscatter lidar used for the present work is located in Villa Martelli near Buenos Aires and is based on Nd: YAG laser transmitter (Continuun - Surelite II) which delivers around $500 \mathrm{~mJ}$ by pulse at $532 \mathrm{~nm}$ with a $10 \mathrm{~Hz}$ pulse rate, $5 \mathrm{~ns}$ pulse duration, with a tilt angle less than $0.6 \mathrm{mrad}$. A dual telescope receiver is used to handle the large signal dynamic range. An $8.2 \mathrm{~cm}$ diameter Cassegrain telescope covers the range between $50 \mathrm{~m}$ to $6 \mathrm{~km}$, while a $50 \mathrm{~cm}$ diameter Newtonian telescope covers from $500 \mathrm{~m}$ up to $28 \mathrm{~km}$. The two telescopes are pointed at zenith. A field of view less than 1.5 mrad is normally used for both telescopes. To avoid possible, unwanted inclusion of altocumulus, i.e., of water clouds, we restricted the present campaign to clouds with a cloud base height $\geq 6 \mathrm{~km}$, a criterion that coincides with the definition of cirrus clouds given by the International Coordination group on Laser Atmospheric Studies (ICLAS): cirrus clouds derived from lidar measurements are layers of particle above $6 \mathrm{~km}$ situated in an air mass with temperature of $-25^{\circ} \mathrm{C}$ or colder which in addition display a large temporal and spatial variability.

\section{Multitropopause Events}

In spite of its essential role in the atmosphere, the tropopause can still present not very well-known behaviours and the thermal structure of the tropopause layer can be quite complex, specially in midlatitude regions [13]. The thermal or lapse-rate tropopause definition is based on the variability in lapse rate in an atmospheric temperature profile. In the most commonly used definition, the conventional tropopause is defined by the World Meteorological Organization (WMO) [23] as the "lowest level at which the lapse rate decreases to $2^{\circ} \mathrm{C} / \mathrm{km}$ or less, provided also the averaged lapse rate between this level and all higher levels within $2 \mathrm{~km}$ does not exceed $2^{\circ} \mathrm{C} /$ $\mathrm{km}$ ". The WMO definition also allows additional tropopauses above the first one if the average lapse rate between any level above the first tropopause and all higher levels within $1 \mathrm{~km}$ exceeds $3^{\circ} \mathrm{C} / \mathrm{km}$. This definition, which is used in the rest of the present study, actually reflects dynamical disturbances to the temperature profile like jet streams or upper-level fronts, resulting in multiple temperature inversions in the UTLS [24] that can lead to tropopause folding and mixing of stratospheric and tropospheric air [11]. Due to the ambiguity of the thermal tropopause definition with respect to the 
different processes involved in both hemispheres [7] which are also used to define it, e.g., chemical tropopause and dynamical tropopause, it should be noted that when we refer to tropopause, the Extratropical Tropopause Layer (ExTL) as explained in Bischoff et al. [25] is considered.

Analysis of 2000 temperature profiles from the Buenos Aires radiosoundings on the 2002-2003 period shows that multiple tropopauses occur in near $30 \%$ of cases, with a third tropopause in $10 \%$ of cases (not shown). Additional tropopauses were considered to be negligible.

Figure 1 shows the annual cycle of MT occurrences, averaged over the 2002-2003 period. The vertical bars (one standard deviation) represent the 2002-2003 interannual variability, confirming the significance of the annual cycle. The tropopause temperature and pressure

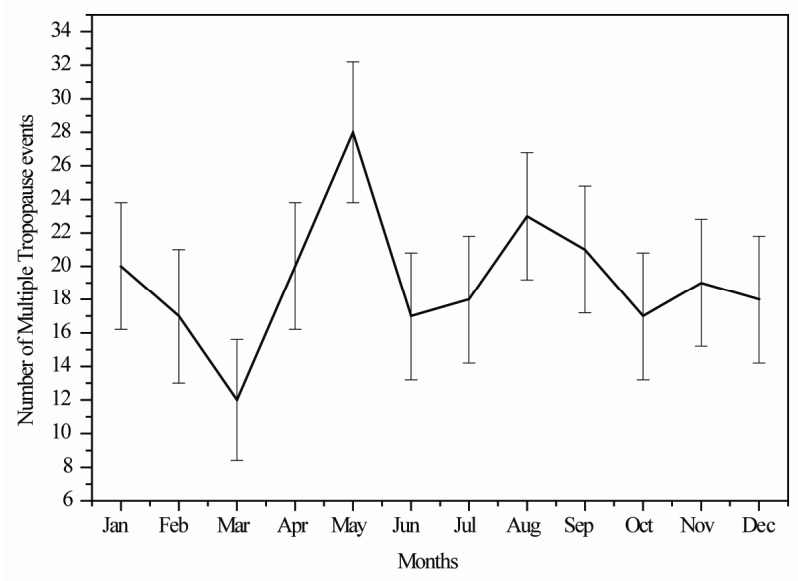

Figure 1. Annual frequencies of multiple tropopauses over Buenos Aires, averaged on 2002-2003 period.

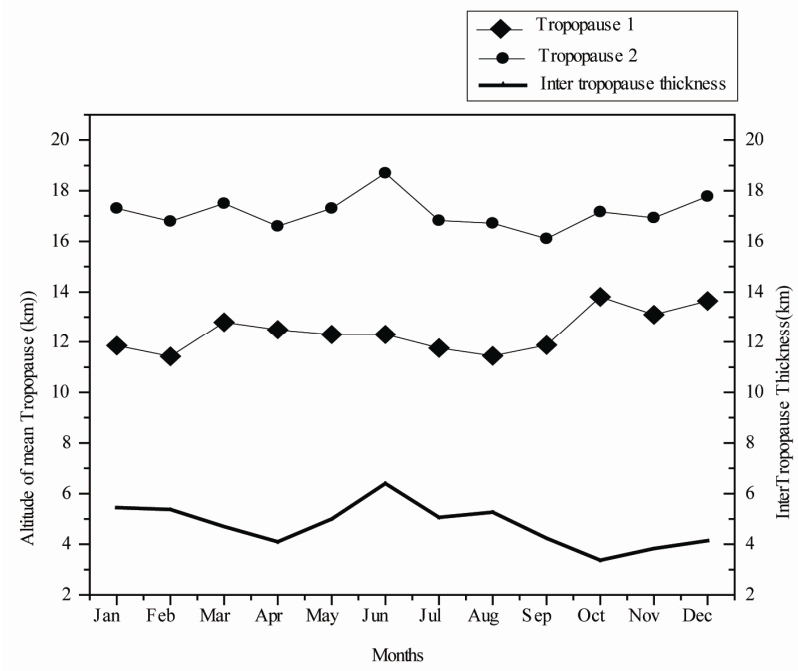

Figure 2. Annual evolution of the mean tropopause altitudes and the mean inter-tropopause thickness (thick line) during the 2002-2003 period. are known to exhibit quasi-biennial oscillation and longterm fluctuations [26] than can affect both the annual cycle and the interannual variability. The annual MT occurrence cycle begins with high occurrences close to $20 \%$ in January, followed by the first minimum in March $(13 \%)$. The first maximum is reached during May with percentages near $29 \%$, followed by a second maximum reached during August (23\%). High MT occurrences in April-June and August-September coincide with the higher occurrences of fronts or jets. These values are consistent with results from Bischoff et al., (2007) who found, based on 9000 rawinsonde data, occurrences over Buenos Aires (EZE) for double tropopause close to $25 \%$ in March and maximum occurrence $(\approx 42 \%)$ in late winter and early spring.

Figure 2 shows the annual cycle of tropopause altitudes and the mean intertropopause thickness (IT) considering only the first and second tropopauses of the data. The IT can be defined as the distance between the lowest and higher tropopauses. The minimum and maximum altitudes are reached in February-September and JuneOctober respectively.

The monthly mean altitude of the first tropopause varies $2.4 \mathrm{~km}$ between February-October (from 11.4 to 13.8), while that of the second tropopause varies almost $2.6 \mathrm{~km}$ (from 18.7 to $16.1 \mathrm{~km}$ ). The IT annual cycle displays a minimum in October $(2.2 \mathrm{~km})$ and two maximum between April-August. These maximums may be correlated with the increase in MT frequency over the same period (Figure 1), but with its first maximum centered in July instead June. The averaged IT thickness spreads from 2.8 $\mathrm{km}$ to $6.4 \mathrm{~km}$.

\section{Cirrus Clouds and Multiple Tropopauses}

The distribution of cirrus occurrence with cloud temperature for the dataset under study (80 cases) shows that cirri population is constrained between $-75^{\circ} \mathrm{C}$ and $-55^{\circ} \mathrm{C}$, with cirrus sightings increasing in the temperature range from $-70^{\circ} \mathrm{C}$ to $-65^{\circ} \mathrm{C}$. Almost the $75 \%$ of these clouds were observed with the relative humidity close to $80 \%$ in average.

As Protat et al. [27] exposed, the frequency of cirrus detection is variable over the year, but it is not possible yet to determine if this is due to a change in the population of cirrus clouds or to sampling effects. It is important to note that even when the lidar was operating continuously some cirrus are sometimes not detected by the system due to the presence of low clouds; therefore the comparison between the occurrence of the tropopause events with the cirrus detected is a pointless exercise. Nevertheless, comparing the properties of multiple tropopause and cirrus clouds on days when both are de- 
tected can reveal correlations between the two phenomena.

This study focuses on the relationship between the tropopause(s) and cirrus clouds. In order to avoid possible, unwanted inclusion of altocumulus, i.e., of water clouds, we restricted the present analysis to clouds with a cloud base height $\geq 7 \mathrm{~km}$, which implies an amount of 41.600 lidar profiles for 2002-2003 period.

The distance between cloud-top altitudes and the lowest tropopause is shown in Figure 3(a) for all clouds with top altitudes above $7 \mathrm{~km}$. Positive (negative) values indicate cloud-top altitudes above (below) the first tropopause. Clearly, most cloud-top altitudes are located below but very close to the first tropopause; that is, cirrus clouds are very likely stuck right under the tropopause and thus, these tropopause cirrus can be viewed as tropopause tracers as was reported by Lakkis et al. [2]. Clouds with tops above the first tropopause occur in $25 \%$ of the observations, out of which almost $90 \%$ occur in MT events; therefore for these cases, a possible relationship between tops and second tropopause disserves to be analyzed. In order to evaluate this correlation and how much of this region is filled by clouds, we use the ratio of the distance between cloud top and first tropopause to the distance between the first and second tropopauses, proposed for Noël and Haefelin [12]. This ratio is 0 for clouds' tops close to the first tropopause and 1 for those close to the second. Figure 3(b) shows the distribution positively skewed of the ratio. In the $75 \%$ of the cases the ratio is below 0.4 , meaning that cloud tops occupy a limited region between the first and second tropopauses, with their top in the lower $40 \%$ of the intertropopause zone, while ratio is above 0.6 in $15 \%$ of the cases which means that these cloud tops span the entire region. No cirrus cloud was detected with a top altitude above the second tropopause; thus it is possible to infer that these clouds live in an unstable temperature profile which contributes a fraction of them to expand vertically until they reach the second tropopause.

Figure 4 shows the distributions of cloud-base altitude for those cloud tops that extend above the first tropopause. As shown in the plot, the distribution appears negatively skewed and cirrus clouds have most frequently their base altitude between 4 and $1 \mathrm{~km}$ below the first tropopause, with a maximum centered close to $2,5 \mathrm{~km}$ below the lower tropopause. By considering Figures 4 and 3(a), it is important to note that all the cirri presented are located close to the first tropopause and below the second tropopause; i.e., cirrus that cross the intertropopause zone, but there are no clouds entirely contained in the intertropopause region. During the whole time of each observation (up to 9 hours), the cloud remains inside the limits defined by the first and second tropopau-

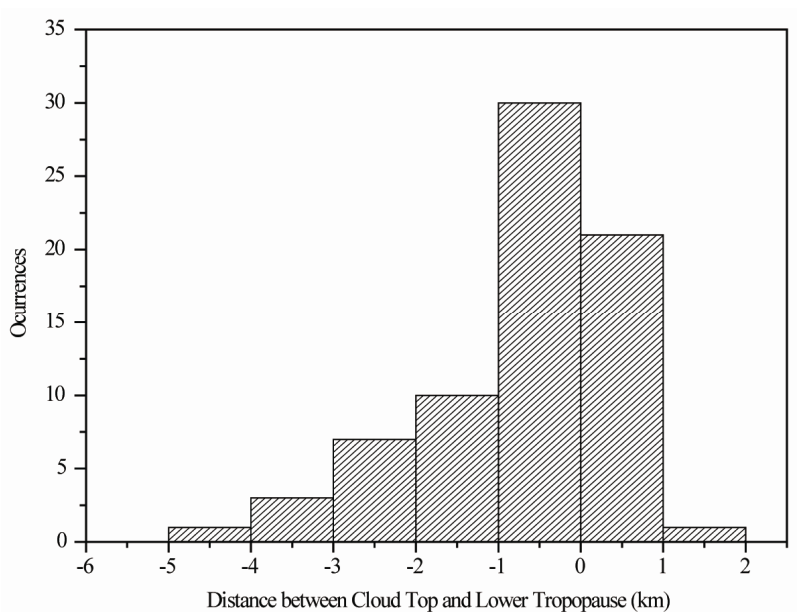

(a)

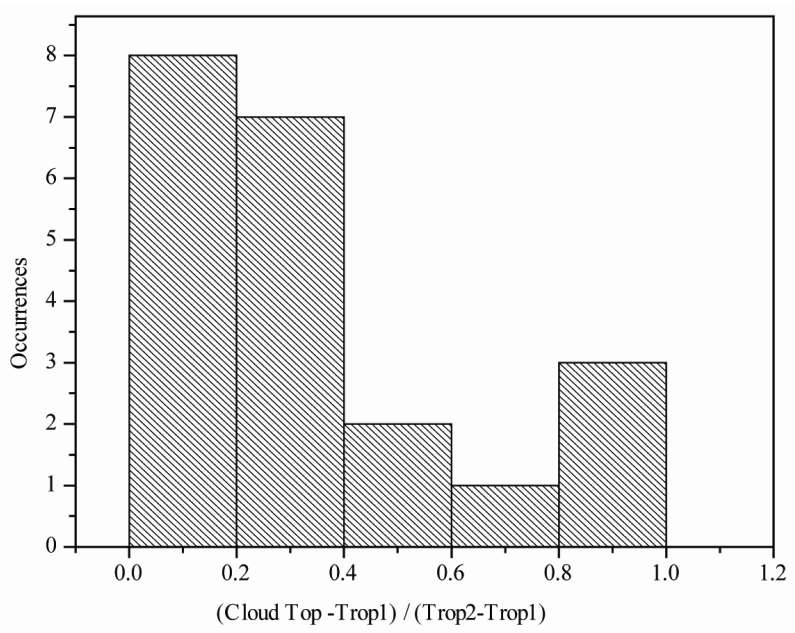

(b)

Figure 3. (a) Distribution of distance between the first tropopause and cross-tropopause cirrus cloud tops, (b) ratio of the cloud top to first tropopause distance on the distance between first and second tropopauses.

ses; therefore the second tropopause seems to act as a cloud-top ceiling. Following the criteria adopted by Noël and Haeffelin [12] and considering clod top and base values it is possible to classify cirrus clouds in two groups defined by the location of their boundaries with respect to the first and second tropopause: the first group with cloud top altitudes below the first tropopause (75\%) as tropospheric cirrus, while the second one, with cloud top altitude within the intertropopause, as cross-cirrus $(25 \%)$.

As an example of the dataset analyzed, a cloud observed on 27 May 2003 is shown in Figure 5(a). The first and second tropopauses are marked with solid lines, at 10.9 and $12.8 \mathrm{~km}$, respectively, and seem to be relevant in the temperature profile from the 12 UT radiosounding 


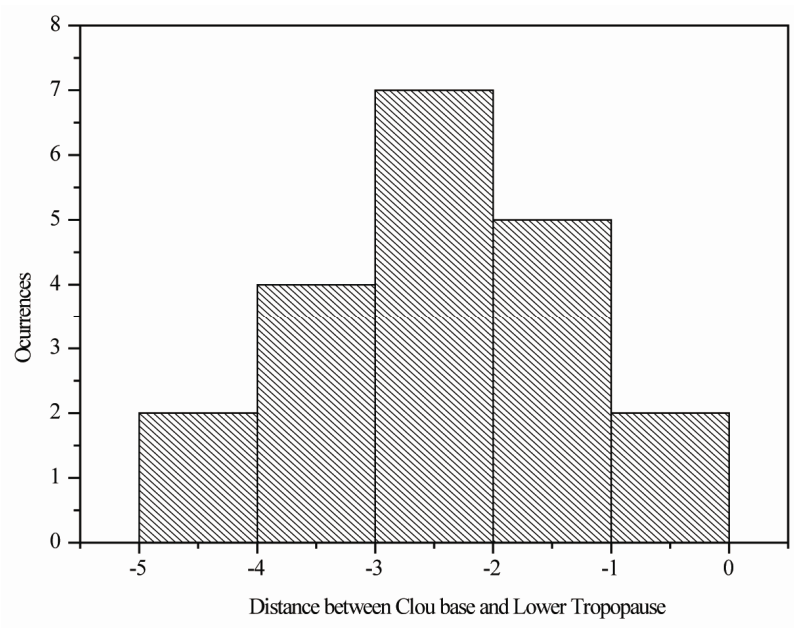

Figure 4. Distribution of distance between cloud base and the first tropopause.

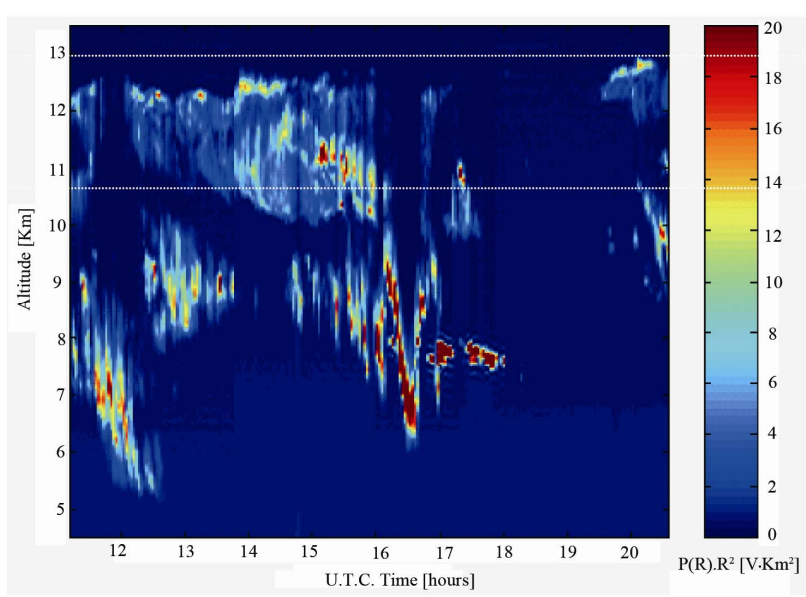

(a)

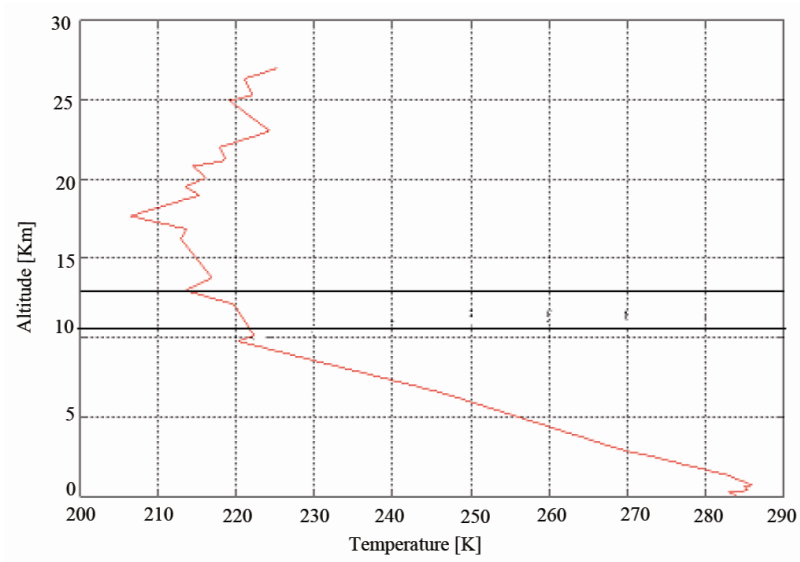

(b)

Figure 5. (a) Backscattering coefficients observed by the lidar on 27 May 2003 as a function of time and altitude, (b) Temperature profile from radiosoundings on 27 May 2003. On both figures, the first two tropopauses are indicated using solid lines.

\section{(Figure 5(b)).}

Finally, we study the geometrical thickness for the cirrus with top above the first tropopause. The distribution of geometrical thickness for cross cirrus is presented in Figure 6. The measured values of geometrical thickness, conforming a negatively skewed distribution of thick cirrus, are found to extend over a range of 1 to $5 \mathrm{~km}$ with peak occurrence $(65 \%)$ confined to a narrow range of 1 to $3 \mathrm{~km}$. Nonetheless these values are not different of those derived from tropospheric cirrus clouds. Figure 7 shows geometrical thickness for all the dataset under analysis. Therefore, it is not possible to highlight specific properties of the cross cirrus compared with the rest of the cirrus population and to establish relationships between thickness and multiple tropopause events could not be argued. However this thickness value confirms them (cross and troposheric cirrus) as thick cirrus, con-

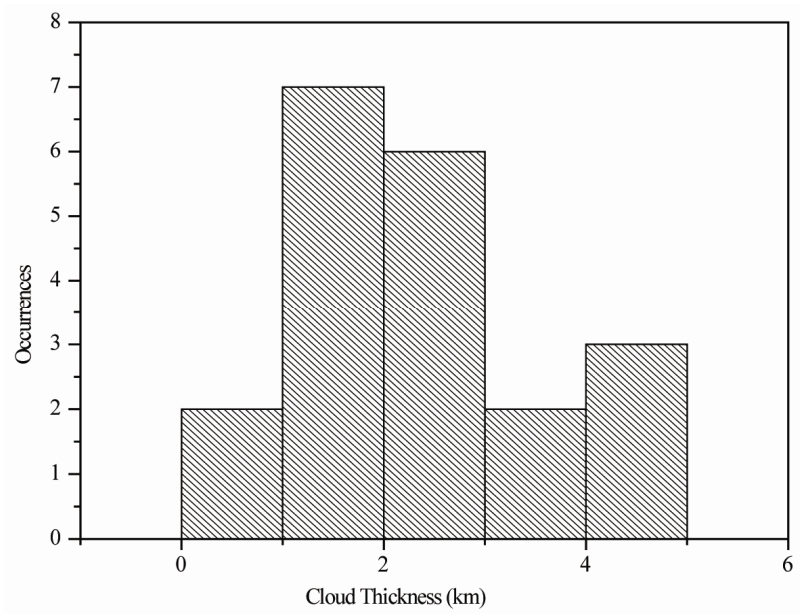

Figure 6. Distribution of cloud geometrical thickness for observations during 2002-2003 for cirrus clouds between the two tropopauses.

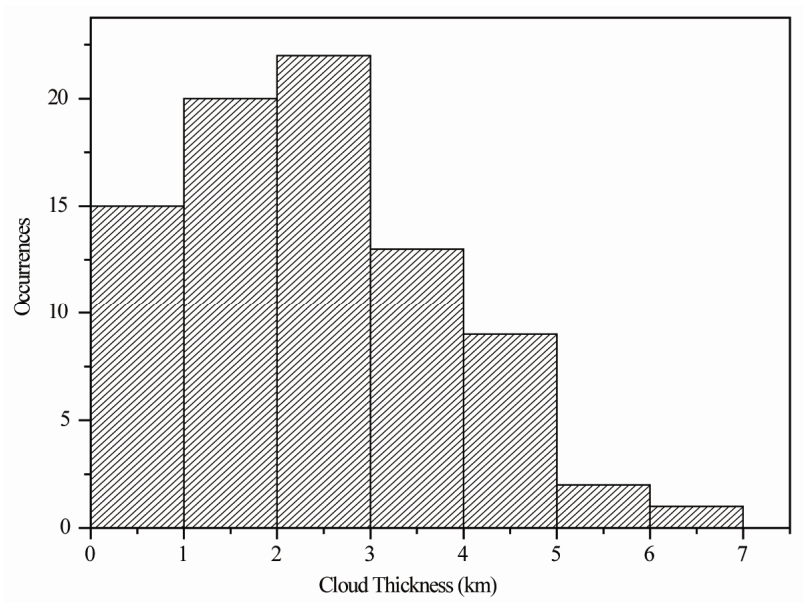

Figure 7. Distribution of cloud geometrical thickness for the whole observations during 2002-2003. 
sidering the standard lidar terminology and it appears the conclusion reached in Lakkis et al. [2] still hold true for the extended dataset.

\section{Conclusions}

In this study multitropopause events related with cirrus clouds were analyzed. Using lidar technique it was possible to compare cirrus cloud-top and bases altitudes.

Regarding the MT events, the annual cycle of MT shows that high MT occurrence appears in April-June and August-September in coincidence with the higher occurrences of fronts or jets. The IT annual cycle picture displays a minimum in October and two maximum between April-August. These maximums may be correlated with the increase in MT frequency over the same period (Figure 1). The averaged IT thickness spreads from 2.8 $\mathrm{km}$ to $6.4 \mathrm{~km}$.

The study of cloud-top and base altitude respect to tropopause altitude reveals that most cirrus clouds are contained below the lower tropopause, but representative part of them crosses the tropopauses. There were not detected cirrus clouds totally contained between the first and second tropopause. The frequency of occurrence of the cirrus clouds increases with decreasing distance between cloud top and the first tropopause as Figure 3(a) shows. With the same trend, clouds are more frequent as cloud bases get closer to the tropopause; nevertheless, the maximum occurrence was found $3-2 \mathrm{~km}$ below the tropopause (Figure 4). These results enhance the conclusions about cirrus as tropopause tracers highlighted in Lakkis et al. [2].

The geometrical thickness values, both the tropospheric and cross cirrus, are found to extend over a range of 1 to $5 \mathrm{~km}$ with peak occurrence confined to a narrow range of 1 to $3 \mathrm{~km}$, therefore it is not possible to differentiate different characteristics for each group of clouds.

\section{References}

[1] S. Solomon, D. Qin, M. Manning, R. B. Alley, et al., "Contribution of Working Group I to the Fourth Assessment Report of the Intergovernmental Panel on Climate Change, 2007," Cambridge University Press, Cambridge, 2007.

[2] S. G. Lakkis, M. Lavorato and P. Canziani, "Monitoring Cirrus Clouds with LIDAR in the Southern Hemisphere: A Local Study over Buenos Aires. 1. Tropopause heights," Atmospheric Research, Vol. 92, No. 1, 2009, pp. 18-26. doi:10.1016/j.atmosres.2008.08.003

[3] S. V. Sunilkumar and K. Parameswaran, "Temperature Dependence of Tropical Cirrus Properties and Radiative Effects," Journal of Geophysical Research, Vol. 110, No. 13, 2005, pp. 1-14.doi:10.1029/2004JD005426.
[4] W. Cantrell and A. Heymsfield, "Production of Ice in Tropospheric Clouds: A Review," Bulletin of the American Meteorological Society, Vol. 62, No. 7, 2005, pp. 2352-2372. doi:10.1175/BAMS-86-6-795

[5] A. J. Heymsfield and L. M. Miloshevich, "Parameterizations for the Cross-Sectional Area and Extinction of Cirrus and Stratiform Ice Cloud Particles," Journal of Atmospheric Sciences, Vol. 60, 2003, pp. 936-956. doi:10.1175/1520-0469(2003)060<0936:PFTCSA $>2.0 . C$ $\underline{\mathrm{O} ; 2}$

[6] J. R. Holton, P. H. Haynes, M. E. McIntyre, A. R. Douglass, R. B. Rood and L. Pfister, "Stratosphere Troposphere Exchange," Reviews of Geophysics, Vol. 33, No. 4, 1995, pp. 403-439. doi:10.1029/95RG02097

[7] T. G. Shepherd, "Issues in Stratospheric-Tropospheric Coupling," Journal of the Meteorological Society of Japan, Vol. 80, No. 4B, 2002, pp. 769-792. doi:10.2151/jmsj.80.769

[8] A. Stohl, P. Bonasoni, P. Cristofanelli, et al., "Stratosphere-Troposphere Exchange: A Review, and What We Have Learned from STACCATO," Journal of Geophysical Research, Vol. 108, No. 2, 2003, pp. 8516-8531. doi:10.1029/2002JD002490

[9] D. J. Seidel and J. W. Randel, "Variability and Trends in the Global Tropopause Estimated from Radiosonde Data," Journal of Geophysical Research, Vol. 111, 2006. doi:10.1029/2006JD007363

[10] S. G. Lakkis and P.O. Canziani, "A Comparative Analysis of the Temperature Behavior and Multiple Tropopause Events Derived from GPS, Radiosonde and Reanalysis Datasets over Argentina, as an Example of Southern Mid Latitudes," Revista de Climatología, Vol. 9, 2009, pp. $1-14$.

[11] K. P. Hoinka, "Statistics of the Global Tropopause Pressure," Monthly Weather Review, Vol. 126, 1998, pp. 3303-3325. doi:10.1175/1520-0493(1998)126<3303:SOTGTP $>2.0 . C$ $\underline{\mathrm{O} ; 2}$

[12] G. C. Reid and K. S. Gage, "A relationship Between the Height of the Tropical Tropopause and the Global Angular Gage Momentum of the Atmosphere," Geophysical Research Letters, Vol. 11, No. 9, 1984, pp. 840-842. doi:10.1029/GL011i009p00840

[13] V. Noël and M. Haeffelin "Midlatitude Cirrus Clouds and Multiple Tropopauses from a 2002-2006 Climatology over the SIRTA Observatory," Journal of Geophysical Research, Vol. 112, No. D13, 2007. doi:10.1029/2006JD007753

[14] McFarquhar, M. Greg, J. Andrew, et al., "Thin and Subvisual Tropopause Tropical Cirrus: Observations and Radiative Impacts," Journal of Atmospheric Sciences, Vol. 57, No. 12, 2000, pp. 1841-1853. doi:10.1175/1520-0469(2000)057<1841:TASTTC $>2.0 . C$ $\underline{\mathrm{O} ; 2}$

[15] T. J. Garrett, B. C. Navarro, C. H. Twohy, et al., "Evolution of a Florida Cirrus Anvil," Journal of Atmospheric Sciences, Vol. 62, No. 7, 2005, pp. 2352-2372. doi:10.1175/JAS3495.1

[16] W. B. Rossow and L. C. Garder, "Cloud Detection Using Satellite Measurements of Infrared and Visible Radiances 
for ISCCP," Journal of Climate, Vol. 6, No .12, 1993, pp. 2341-2369.

doi:10.1175/1520-0442(1993)006<2341:CDUSMO $>2.0$. $\mathrm{CO} ; 2$

[17] N. Naud, M. Haeffelin, P. Muller, Y. Morille and A. Delaval, "Assessment of MISR and MODIS Cloud Top Heights through Comparison with a Back-Scattering Lidar at SIRTA," Geophysical Research Letters, Vol. 31, 2004. doi:10.1029/2003GL018976

[18] J.-F. Daloze and M. Haeffelin, "Validation of SAFNWC/MSG Cloud Top Height Using Ground-Based Lidar and Radar Measurements," Visiting Scientist Report, CMS Lannion, 2005.

[19] M. H. Chiriaco, Chepfer, V. Noël, A. Delaval, M. Haeffelin, P. Dubuisson and P. Yang, "Improving Retrievals of Cirrus Cloud Particle Size Coupling Lidar and Three-Channel Radiometric Techniques," Monthly Weather Review, Vol. 132, 2004, pp. 1684-1700. doi:10.1175/1520-0493(2004)132<1684:IROCCP $>2.0 . C$ $\underline{\mathrm{O} ; 2}$

[20] K. Sassen, "The Polarization Lidar Technique for Cloud Research: A Review and Current Assessment," Bulletin of the American Meteorological Society, Vol. 72, No. 12, pp. $1848-866$. doi:10.1175/1520-0477(1991)072<1848:TPLTFC $>2.0 . C$ $\underline{\mathrm{O} ; 2}$

[21] Z. Wang and K. Sassen, "Cloud Type and Macrophysical Property Retrieval Using Multiple Remote Sensors," Journal of Applied Meteorology, Vol. 40, No. 10, 2001, pp. $1665-1682$. doi:10.1175/1520-0450(2001)040<1665:CTAMPR $>2.0$. $\underline{\mathrm{CO} ; 2}$
[22] V. Noël, H. Chepfer, M. Haeffelin and Y.Morille, "Classification of Ice Crystal Shapes in Midlatitude Ice Clouds from Three Years of Lidar Observations over the SIRTA Observatory," Journal of the Atmospheric Sciences, Vol. 63, No. 11, 2006, pp. 2978-2991.

[23] WMO, "Definition of the Tropopause," WMO Bulletin, No. 6, 1957, p. 136.

[24] M. A. Shapiro, "Turbulent Mixing within Tropopause Folds as a Mechanism for the Exchange of Chemical Contituents between the Stratosphere and Troposphere," Journal of the Atmospheric Sciences, Vol. 37, No. 5, 1980, pp. 994-1004. doi:10.1175/1520-0469(1980)037<0994:TMWTFA $>2.0$. $\mathrm{CO} ; 2$

[25] S. A. Bischoff, P. O. Canziani and A. E. Yuchechen, "The Tropopause at Southern Extra Tropical Latitudes: Argentina Operational Rawinsonde Climatology," International Journal of Climatology, Vol. 27, No. 2, 2007, pp. 189-209. doi: $10.1002 /$ joc. 1385

[26] J. K. Angell and J. Korshover, "Quasi-biennial and Long-Term Fluctuations in Tropopause Pressure and Temperature, and the Relation to Stratospheric Water Vapor Content," Monthly Weather Review, Vol. 102, No. 1, 1974, pp. 29-34. doi:10.1175/1520-0493(1974)102<0029:QBALTF $>2.0 . \mathrm{C}$ $\underline{\mathrm{O} ; 2}$

[27] A. Protat, M. Haeffelin, A. Armstrong, Y. Morille, J. Pelon, J. Delanoë and D. Bouniol, "Impact of Conditional Sampling and Instrumental Limitations on the Statistics of Cloud Properties Derived from Cloud Radar and Lidar at SIRTA," Geophysical Research Letters, Vol. 33, 2006. doi:10.1029/2005GL025340 